\title{
Relapsing Neuropathy Associated with Hepatitis C Virus Infection
}

\author{
Kenichi Kashinara, Tadashi Terai and Toshikiyo Shomori
}

\begin{abstract}
A patient with hepatitis $\mathrm{C}$ virus $(\mathrm{HCV})$ infection developed neuropathy characterized by recurrent attacks of anesthesia, dysaesthesia, mild weakness and swelling of the right forearm. Serological examinations suggested an abnormal autoimmune state. HCV infection might produce neuropathy by inducing abnormal autoimmunity. (Internal Medicine 34: 265-266, 1995)
\end{abstract}

Key words: mononeuritis multiplex, vasculitis, immune complex

\section{Introduction}

Hepatitis $\mathrm{C}$ virus (HCV) infection is often reported in association with abnormal autoimmunity (1-5). Here we describe a patient with relapsing neuropathy associated with $\mathrm{HCV}$ infection and laboratory data suggesting abnormal autoimmunity.

\section{Case Report}

A 65-year-old woman was referred because of numbness in her right forearm. She had been healthy until the age of 30 , when she had developed increasing general malaise. One month later, numbness in the right toe had developed and spread to the right distal leg, which made it difficulf for her to walk. The patient was diagnosed as having acute hepatitis, which was later found to be chronic type $\mathrm{C}$ hepatitis, and subsequently followed up. Interferon was not administered for treatment of her condition. The sensory and motor disturbance in the right leg diminished within a month, although mild symptoms persisted.

At noon on November 13, 1993, the patient noticed sudden numbness and pain in the right forearm, and was referred to us on December 1. Neurologic examination revealed anesthesia and dysaesthesia in the right distal leg, and anesthesia and painful dysaesthesia in the right forearm with a distribution coincident with the superficial distributions of median and radial nerves. Muscle strength was reduced slightly in the right upper and lower limbs. Grip power was $12 \mathrm{~kg}$ for the right hand and $29 \mathrm{~kg}$ for the left. The muscle weakness in the lower limbs was most prominent in the right tibialis anterior (4/5). The forearm was swollen. The reflexes were normal.
Liver enzyme levels were elevated slightly, hepatitis $\mathrm{C}$ virus $(\mathrm{HCV})$ antibody titer was more than $10.8 \mathrm{IU} / \mathrm{L}$, serum $\mathrm{IgG}$ level was $2,738 \mathrm{mg} / \mathrm{dL}$ (normal; 1,000-2,100), rheumatoid factor was $43.1 \mathrm{U} / \mathrm{mL}(<5)$, C1q-binding immune complex was 6.9 $\mu \mathrm{g} / \mathrm{mL}(<3)$, C3-binding immune complex was $22.1 \mu \mathrm{g} / \mathrm{mL}$ $(<13)$, antinuclear antibody was 1:80 $(<1: 20)$, CH50 was less than $12 \mathrm{U} / \mathrm{mL}(30-40)$, and the proportion of CD8+lymphocytes was reduced. The erythrocyte sedimentation rate and blood sugar level were normal. Hepatitis B virus markers, C-reactive protein, cryoglobulin, and anti-ds DNA, anti-Sm, anti-SS-A, anti-SS-B, and anti-neutrophyl cytoplasmic antibodies were negative. A nerve conduction study was performed on December 2 . Motor conduction velocity was $59.3 \mathrm{~m} / \mathrm{s}$ for the right median nerve, $60.6 \mathrm{~m} / \mathrm{s}$ for the right ulnar nerve, and $40.0 \mathrm{~m} / \mathrm{s}$ for the right posterior tibial nerve. Sensory nerve conduction velocity was $45.1 \mathrm{~m} / \mathrm{s}$ for the right median nerve and $35.8 \mathrm{~m} / \mathrm{s}$ for the right sural nerve, being slightly reduced in comparison with the motor nerves.

Medication with $1.5 \mathrm{mg} /$ day mecobalamine and $40 \mathrm{mg} /$ day aspirin was started, and within one week the sensory and motor disturbances were alleviated. However, anesthesia, painful dysaesthesia and swelling in the right forearm recurred on December 16, 1993, and on January 3, 13, and 25, 1994, but these were alleviated within one or two weeks each time. A CSF examination, performed on January 21,1994 , revealed a normal protein concentration of $31 \mathrm{mg} / \mathrm{dl}$ and one mononuclear cell $/ 3 \mathrm{~mm}^{3}$. Another nerve conduction study was performed on January 20,1994 , and this revealed a motor nerve conduction velocity and an evoked potential amplitude of $59.3 \mathrm{~m} / \mathrm{s}$ and 2.2 $\mathrm{mV}$, respectively, for the right median nerve, $62.5 \mathrm{~m} / \mathrm{s}$ and 2.0 $\mathrm{mV}$ for the right ulnar nerve, and $46.2 \mathrm{~m} / \mathrm{s}$ and $5.0 \mathrm{mV}$ for the

From the Department of Neurology, Okayama University Medical School, Okayama Received for publication May 2, 1994; Accepted for publication November 7, 1994

Reprint requests should be addressed to Dr. Kenichi Kashihara, the Department of Neurology, Okayama University Medical School, 2-5-1 Shikata-cho, Okayama 700 
right posterior tibial nerve. Sensory nerve conduction velocity and the amplitude of evoked potential were $51.8 \mathrm{~m} / \mathrm{s}$ and $10 \mu \mathrm{V}$ for the right median nerve and $50.0 \mathrm{~m} / \mathrm{s}$ and $10 \mu \mathrm{V}$ for the right sural nerve. Although the conduction velocities were within the normal range, the amplitude of both motor and/or sensory evoked potentials for the median and ulnar nerve on the right side were $50-60 \%$ of those on the left. These results suggested that axonopathy was the cardinal pathological change in the peripheral nervous system in this patient. Thermography showed a reduced surface temperature at the right hand. Magnetic resonance imaging of the brain and electroencephalography revealed normal findings. A right sural nerve biopsy was carried out on January 24, 1994. Light and electron microscopic examinations of the specimen revealed normal myelinated fibers and interstitial tissue. A nerve fiber diameter histogram revealed reduced numbers for the 4 and $10 \mu \mathrm{m}$ diameter classes.

\section{Discussion}

The present patient developed neuropathy in the right distal leg and right forearm during the course of HCV infection. Because the symptoms in the right leg had a long history, detailed records were not available. Also, as the symptoms disappeared soon after the first examination, discussion of the pathogenesis of neuropathy in the present case will focus on the symptoms in the right forearm.

The neurological symptoms in the present case were characterized by relapsing and asymmetric sensory-dominant neuropathy. The results of physical examination and the nerve conduction study suggested that the right median, ulnar, and radial nerves were involved to various degrees, producing mononeuritis multiplex.

With regard to previous cases of neuropathy associated with HCV infection, Sakajiri and Takamori (6) reported a patient with multiple mononeuropathy which occurred during administration of interferon for treatment of chronic hepatitis $\mathrm{C}$. They discussed the role of interferon in the pathogenesis of the neuropathy. In the present case, however, interferon was not used, thus cause of the neuropathy was different from their case.

Authier et al (5) reported 10 patients with cryoglobulinemic neuropathy, among whom 9 showed sensory neuropathy and one showed mononeuritis multiplex, associated with HCV infection. Several authors have pointed out a high incidence of $\mathrm{HCV}$ infection in patients with cryoglobulinemia $(3,4)$. In the present case, although circulating immune complexes were recognized, cryoglobulin was not detected. Although the features of the abnormal autoimmune state were not characteristic of any of the collagen diseases, they may have been associated with the cause of the neuropathy.

Autoimmunity-mediated vasculitis of the vaso nervorum has been reported to produce mononeuritis multiplex. For example, hepatitis B antigen has often been reported in association with polyarthritis nodosa, which complicated mononeuritis multiplex due to vasculitis (7). On the other hand, HCV is not suggested to play a significant role in the pathogenesis of vasculitis (8). However, circulating immune complexes have been detected frequently in patients with not only type-B but also non-A, non-B hepatitis (9). Several authors have reported vasculitis of the skin as a complication of HCV infection $(1,2)$. An abnormal autoimmune state, produced in association with $\mathrm{HCV}$ infection, may play some role in the pathogenesis of vasculitis (2), which in turn could produce neuropathy. Although the biopsy sample of the sural nerve did not show the histology of vasculitis, the clinical features of the present case, such as acute onset, asymmetric neuropathy with painful dysaesthesia, swelling, and nerve conduction findings suggesting axonopathy, are consistent with vasculitic neuropathy. It is suggested that the HCV infection in the present case may have been responsible for the production of neuropathy via abnormal autoimmunity. Thus, neurologic involvement should be borne in mind as a possible extrahepatic complication of $\mathrm{HCV}$ infection.

\section{References}

1) Hearth-Holmes M, Zahradka SL, Baethge BA, Wolf RE. Leukocytoclastic vasculitis associated with hepatitis C. Am J Med 90: 765, 1991.

2) Durand JM, Lefevre P, Harle JR, Boucrat J, Vitvitski L, Soubeyrand J. Cutaneous vasculitis and cryoglobulinaemia type II assoicated with hepatitis C virus infection. Lancet 337: 499, 1991.

3) Dammacco F, Sansonno D, Antibodies to hepatitis $C$ virus in essential mixed cryoglobulinaemia. Clin Exp Immunol 87: 352, 1992.

4) Misiani R, Bellavita P, Fenili D, et al. Hepatitis $C$ virus infection in patients with essential mixed cryoglobulinemia. Ann Intern Med 117: $573,1992$.

5) Authier FJ, Pawlotsky JM, Viard JP, Guillivin L, Degos JD, Gherardi RK. High incidence of hepatitis $C$ virus infection in patients with cryoglobutinemic neuropathy. Ann Neurol 34: 749, 1993.

6) Sakajiri K, Takamori M. Multiple mononeuropathy during recombinant interferon-alpha 2a therapy for chronic hepatitis C. Rinsho Shinkei Gaku 32: 1041, 1992 (in Japanese).

7) Gocke DJ, Hsu K, Morgan C, Bombardieri S, Lockshin M, Christian CL. Association between polyarteritis and Australian antigen. Lancet ii: 1149, 1970.

8) Theilmann L, Gmelin K, Kallinowski B, Kommerell B, Koderisch J, Andrassy K. Prevalence of antibodies to hepatitis $\mathrm{C}$ virus in sera from patients with systemic necrotizing vasculitis. Nephron 57: 482, 1991.

9) Dienstag JL. Bhan AK, Alter HJ, Feinstone SM, Purcell RH. Circulating immune complexes in non-A, non-B hepatitis. Lancet i: 1256, 1979. 